Original Research Paper

\title{
Durum Wheat Seed Germination Response to Hydrogel Coatings and Moisture under Drought Stress
}

\author{
${ }^{1,2}$ Maya Hotta, ${ }^{1,3}$ James Kennedy, ${ }^{1}$ Clement Higginbotham and ${ }^{1,2}$ Noreen Morris \\ ${ }^{I}$ Materials Research Institute, Athlone Institute of Technology, Dublin Road, Athlone, Co. Westmeath, Ireland \\ ${ }^{2}$ Department of Life and Physical Sciences, Athlone Institute of Technology, Dublin Road, Athlone, Co. Westmeath, Ireland \\ ${ }^{3}$ Centre for Industrial Services and Design, Athlone Institute of Technology, Dublin Road, Athlone, Co. Westmeath, Ireland
}

Article history

Received: 15-10-2015

Revised: 24-03-2016

Accepted: 27-04-2016

Corresponding Author:

Noreen Morris

Department of Life and

Physical Sciences, Athlone

Institute of Technology,

Athlone, Ireland

Email: nmorris@ait.ie

\begin{abstract}
Technologies that can increase crop production while maintaining low pollution are essential for sustainable agriculture. This study compares the germination performance of Durum wheat seeds (Triticum durum Desf.) which were coated with synthetic coatings [polyacrylamide (PA)] and novel natural coatings [mixtures of agar/lcarrageenan $(\mathrm{AC})$ ] at different moisture levels. A number of germination performance indicators were measured for each of the categories of coatings. These included: (i) \% germination, (ii) radicle emergence, (iii) speed of germination, (iv) seedling length, (v) fresh seed weight and (vi) seed vigour index. Results showed that both the synthetic and natural coatings improved germination performance in the Durum wheat seeds versus the untreated seeds when non-drought ( $80 \%$ moisture) conditions were used. However, when $40 \%$ moisture levels were used, the natural coated seeds showed a $6 \%$ improvement in germination performance over the synthetic PA coated seeds. This improved germination performance under drought stress along with the fact that these novel AC coatings used are completely natural and environmentally friendly suggests that these novel coatings have a big future in seed coatings, especially in countries which experience drought conditions and are dependent on natural irrigation.
\end{abstract}

Keywords: Drought Test, Triticum Durum Wheat, 1-Carrageenan, Polyacrylamide, Seed Coating

\section{Introduction}

There is a demand to use environmentally friendly seed coatings made from natural polymers due to contamination of soils and the surrounding environment with toxic and persistent materials (Zeng and Wang, 2010; Zeng and Zhang, 2010). With climate change and the unpredictability of rainfall, the development of green technologies that can provide both environmental protection and drought resistance in crops has become a matter of great importance (Guan et al., 2014; Kneipp, 2008).

This project uses water-absorbent polymers as seed coating materials in order to support sustainable agriculture and provide solutions to the food crisis. The work investigates the difference in seed germination and seed vigour of Durum wheat seeds coated with a synthetic linear Polyacrylamide (PA) polymer versus a novel Agar/l-Carrageenan (AC) blended natural hydrogel. Tests were undertaken using ideal growth conditions (80\% moisture levels) and simulated drought conditions ( $40 \%$ moisture levels) in the laboratory.

Recent weather problems, particularly drought, have resulted in a decrease in agricultural production yield worldwide (FAO, 2016; NASA, 2015; ZernoExport, 2013). In some countries wheat production has reduced in situations where drought has been severe (Kneipp, 2008; Nijhuis, 2014; Taylor and Koo, 2012). Reduced seed germination due to these drought conditions has contributed significantly lower wheat yields. Seed suppliers have attempted to address this problem by producing a new class of seed coating called SuperAbsorbent hydrophilic Polymers (SAPs) which include PA polymers. The mechanism of action of these polymer coatings to aid the seed germination process depends on their chemical composition and how they are applied on the seeds (Ekebafe et al., 2011; Landis and Haase, 2012; Puoci et al., 2008; Rudzinski et al., 2002; Yang et al., 2014; Zohuriaan-Mehr and Kabiri, 2008). 
Some seed coatings based on SAPs can help improve percentage germination, speed up germination time, promote root/shoot development in the early stages of plant growth and accelerate the harvest time (Akelah, 2013). SAPs used in agriculture are categorised into synthetic, modified-natural and natural polymers. Polyacrylamide (PA) is a synthetic polymer that can be synthesised into either a linear or a gelling system (Fig. 1). Linear PAs are used for erosion control, canal sealing and water clarification, whereas gel-forming cross linked PAs are used in horticulture and are commonly referred to as hydrogels (Landis and Haase, 2012). Synthetic polymers have the benefit of being mechanically strong and long-lasting compared to natural polymers. PA itself does not pose any environmental threat (Seybold, 1994) and is subject to thermal and photo-degradation processes as well as mechanical breakage by soil cultivation. However, the residual acrylamide (AAm) content in PA is a concern. The monomer is a potentially carcinogenic material and a known neurotoxin to humans and animals (Sojka et al., 2007). The U.S. Food and Drug Administration (FDA) regulates the amount of residual AAm to be less than $0.05 \%$ in PA resin for food treatment for human consumption (FDA, 2015; Seybold, 1994; Sojka et al., 2007). Nevertheless acrylamide does not accumulate in soil and it is hydrolysed into less harmful chemicals (Seybold, 1994). Purification of polyacrylamides to<smiles>CCC(CC)C(N)=O</smiles>

Linear PA remove residual monomers and increase its stability is a main concern (Caulfield et al., 2003) dealing with which increases manufacturing costs substantially.

Natural polymers are preferred to synthetic polymers as they are inert, safe, non-toxic, biocompatible, biodegradable, low costing, eco-friendly and abundantly available in nature (Prajapati et al., 2014). However, their chemical composition tends to be complex and varied from batch-to-batch. They are also mechanically weaker and more susceptible to degradation than synthetic polymers (Martin et al., 2011; Puoci et al., 2008). Carrageenans and agar are natural polymers derived from red seaweeds widely used in the food, cosmetic and pharmaceutical industries (Imeson, 2000; Meena et al., 2009; Pereira et al., 2003; Prajapati et al., 2014). These polysaccharides have the ability to form hydrogels when dissolved in hot water (over $85^{\circ} \mathrm{C}$ ) and left to cool. The strength and gel forming ability of these galactose-containing polysaccharides depends on the level of sulphate ester $\left(\mathrm{O}-\mathrm{SO}_{3}{ }^{-}\right)$groups present in the structure. The 1-carrageenan used in this study is a highly sulphated polysaccharide compared to agar (Cregut and Rondags, 2013; Cyber Colloids Ltd, n.d.; Imeson, 2000; Rocha et al., 2014; Smith and Hong-Shum, 2003) and this structure gives a relatively soft and elastic gel, while agar tends to form a stronger and less elastic gel (Lyons et al., 2009) (Fig. 2).

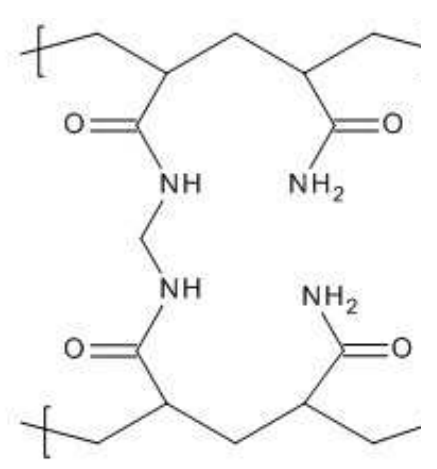

\section{Crosslinked PA}

Fig. 1. The chemical structure of linear polyacrylamide (left) and gel-forming polyacrylamide (right)

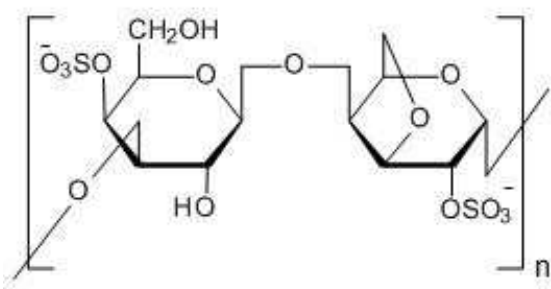

Iota-carrageenan

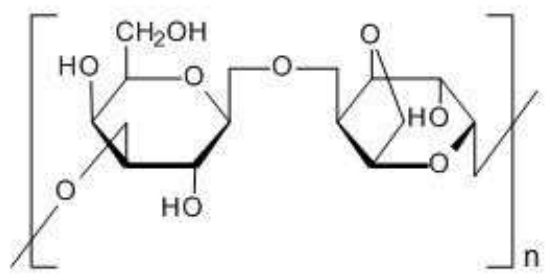

Agarose (Agar)

Fig. 2. The chemical structure of -carrageenan (left) and agar (right) 


\section{Materials and Methods}

The effect of two coating agents (Table 1) including polyacrylamide (PA) and agar/l-carrageenan blend (AC) on Durum wheat seeds germination was investigated under laboratory conditions in two different moisture levels. All samples were pre-chilled for one day at $6^{\circ} \mathrm{C}$ and then transferred into an incubator maintained at a constant temperature of $20 \pm 2^{\circ} \mathrm{C}$ for a total of 7 days, having a day/night cycle of $8 / 16 \mathrm{~h}$.

The seeds were coated using a Satec Concept ML 200 seed coating machine.

\section{Seed Germination Tests under High Moisture Level}

The experiment was carried out in $80 \%$ moisture to provide ideal growth conditions for Durum wheat seeds following the International Seed Testing Association guidelines (ISTA, 2015). The purpose of this study was to investigate the effect of polymer coating volumes and polymer coating types on the germination of seeds.

Ten plastic boxes containing a pleated sheet (with moisture level adjusted to $80 \%$ ) were used to establish ten treatments in a two-factor, randomised block design with four replicates. Hundred seeds were sown in each sheet. The treatments included 5 levels of coating volumes; $0,2,4,8$ and $16 \mathrm{~mL}$ and two types of polymer coating formulations; PA and AC (Table 2).

\section{Seed Germination Tests under Low Moisture Level}

The experiment was carried out in $40 \%$ moisture to simulate drought condition on Durum wheat seeds. The purpose of this study was to compare the germination response of Durum wheat seeds between untreated seeds (control) and polymer coated seeds under less than ideal growth conditions. A randomised block design with a single factor consisting of 3 treatments; Control, $16 \mathrm{~mL}$ of PA treated seeds (PA16) and $16 \mathrm{~mL}$ of AC treated seeds (AC16) were employed in this study (Table 2). For each treatment type, eight rolled paper towels (adjusted to $40 \%$ moisture) containing 25 seeds were prepared and placed in a sealed container to retain the moisture. This test was run in triplicate.

\section{Seedling Measurements}

The Radicle emergence (RE), Germination Speed Index $(G S I)$, Germination percentage $(G)$, fresh Seed Weight $(S W)$, Seedling Length $(S L)$ and Seed Vigour Index $(S V I)$ were measured for each of the categories of coating as seed growth indices.

$G S I, G, S W$ and $S V I$ were calculated by using Equation 1-4 (Bonfim et al., 2010; Kharkale et al., 2011):

$$
\begin{aligned}
& G S I=\sum \frac{G n}{D n} \\
& G(\%)=\left(\frac{G a}{N n}\right) \times 100 \\
& S W(g / g)=\left(\frac{W f}{W i}\right) \\
& S V I=[(\text { plumule }+ \text { root length }) \mathrm{mm}] \times G(\%)
\end{aligned}
$$

Where:

$G n=$ The total number of germinated seeds observed daily

$D n=$ The number of days after incubation

$G a=$ The number of normal germinating seeds recorded on the 7th day after incubation

$N n=$ The total number of experimental seeds per paper towel

$W f=$ The average weight of the seedlings

$W i=$ The average weight of the dry seeds before the germination test

Table 1. Composition of natural and synthetic seed coating solutions

\begin{tabular}{llll}
\hline Sample code & l-Carrageenan $(\% \mathrm{w} / \mathrm{v})^{*}$ & Agar $(\% \mathrm{w} / \mathrm{v})$ & Polyacrylamide $(\% \mathrm{w} / \mathrm{v})$ \\
\hline PA & - & - & 1.5 \\
AC & 1 & 0.5 & -
\end{tabular}

*The $\%$ concentrations are based on solids dissolved in distilled water $(\mathrm{g} / 100 \mathrm{~mL})$

Table 2. Coating types and polymer application rates used for wheat seed coatings

\begin{tabular}{llc}
\hline Sample code & Coating type & Coating volume $^{*}(\mathrm{~mL})$ \\
\hline Control & none & 0 \\
PA2 & $(1.5 \% \mathrm{w} / \mathrm{v})$ polyacrylamide & 2 \\
PA4 & $(1.5 \% \mathrm{w} / \mathrm{v})$ polyacrylamide & 4 \\
PA8 & $(1.5 \% \mathrm{w} / \mathrm{v})$ polyacrylamide & 8 \\
PA16 & $(1.5 \% \mathrm{w} / \mathrm{v})$ polyacrylamide & 16 \\
AC2 & $(1.5 \% \mathrm{w} / \mathrm{v})$ agar/l-carrageenan & 2 \\
AC4 & $(1.5 \% \mathrm{w} / \mathrm{v})$ agar/l-carrageenan & 4 \\
AC8 & $(1.5 \% \mathrm{w} / \mathrm{v})$ agar/l-carrageenan & 8 \\
AC16 & $(1.5 \% \mathrm{w} / \mathrm{v})$ agar/l-carrageenan & 16 \\
\hline
\end{tabular}

*The coating application rates are based on seed weight per volume $\left(48 \mathrm{~g} \mathrm{~mL}^{-1}\right)$ 
The $R E$ was measured on the 3rd day of incubation $\left(20 \pm 2{ }^{\circ} \mathrm{C}\right)$. The $G S I$ was measured by counting the numbers of emerged seedlings on a daily basis starting from the 3rd day of incubation until the end of the test period. Seeds were considered to have germinated when the radicle was over $2 \mathrm{~mm}$ long (Lamhamdi et al., 2011). The $G, S L, S W$ and the $S V I$ were measured on the 7 th day. The seedling length was measured for 30 seedlings from each treatment. Seed lots producing taller seedlings and higher SVI were considered more vigorous than the seed lots producing shorter seedlings and lower SVI (Gupta, 1993).

\section{Statistical Analysis}

A two-way Analysis of Variance (ANOVA) followed by post-hoc Tukey's test was used to determine the effect of factor one (Coating type) and factor two (Coating volume) on seeds. Factor one has 2 levels of coating type; polyacrylamide and agar/l-carrageenan blend. Factor two has 5 levels of coating volume; $0,2,4,8$ and $16 \mathrm{~mL}$. In $40 \%$ moisture conditions, one-way ANOVA with Tukey's test was used to compare the seed response to the coating material. All the estimations were analysed and the values expressed as mean \pm standard error. Statistical significance was defined as $P$-values of 0.05 . All analysis was conducted using the statistical package Minitab ${ }^{\circledR} 16$ (Minitab Inc, State College, United States).

\section{Results}

Comparison of Growth Response between the Control and Polyacrylamide Coated Seeds

There was no significant difference in $G$ and $S L$ between the different levels of PA coatings and the control seeds $(p>0.05)$ at $80 \%$ moisture level. However, a significant difference was observed in the $R E\left(F_{4,15}=\right.$
7.15, $P=0.002)$, the $G S I\left(F_{4,15}=5.42, P=0.007\right)$ and the $\operatorname{SVI}\left(F_{4,95}=2.81, P=0.03\right)$ between the PA2 coated seeds and the control seeds. In the $R E$ measurement, the germination rate of the control seeds were significantly lower than all the other coated seeds and for the GSI, the coated seeds PA2, PA4 and PA16 were significantly higher when compared to the control seeds. The SVI values were shown to display a significant difference between the PA2 and PA16 treated seeds, suggesting that higher PA volumes give better growth response for the Durum wheat seeds (Table 3).

\section{Comparison of Growth Response between Control and Agar/l-Carrageenan Coated Seeds}

There was no statistically significant difference in any of the collected data among the control and the AC coated seeds $(p>0.05)$. The mean values given in Table 4 shows that AC8 and AC16 samples have the highest means in terms of $S L$ and $S V I$, while the highest means for $R E, G S I$ and $G$ tended to concentrate more on AC2 samples, but none were statistically significant values.

\section{Comparison of Growth Response between Different Levels of Polyacrylamide and Agar/l-Carrageenan Coated Seeds}

The effect of seed coating type and various seed coating volume on the performance of seed growth was investigated based on the following parameters; $R E, S L$, $G, G S I$ and SVI.

The $R E$ was significantly affected by the coating types $\left(F_{1,24}=6.16, P=0.02\right.$; Fig. $\left.3 \mathrm{~A}\right)$. Coating AC gave a significantly higher germination rate when compared to the PA coated seeds. However, there was insufficient evidence to show that the difference in coating volume affected the $R E$ of the seeds.

Table 3. Effect of varying polyacrylamide (PA) coating concentrations on seed growth at $80 \%$ moisture

\begin{tabular}{llllll}
\hline Sample code & $R E(\%)$ & $G S I$ & $G(\%)$ & $S L(\mathrm{~cm})$ & $S V I$ \\
\hline Control & $75^{\mathrm{a}^{*}}$ & $29.0^{\mathrm{a}}$ & $91^{\mathrm{a}}$ & $17.03^{\mathrm{a}}$ & $1550^{\mathrm{ab}}$ \\
PA2 & $86^{\mathrm{b}}$ & $30.8^{\mathrm{b}}$ & $92^{\mathrm{a}}$ & $16.62^{\mathrm{a}}$ & $1533^{\mathrm{b}}$ \\
PA4 & $87^{\mathrm{b}}$ & $30.9^{\mathrm{b}}$ & $93^{\mathrm{a}}$ & $1619^{\mathrm{ab}}$ \\
PA8 & $85^{\mathrm{b}}$ & $30.2^{\mathrm{ab}}$ & $92^{\mathrm{a}}$ & $16.92^{\mathrm{a}}$ & $1553^{\mathrm{ab}}$ \\
PA16 & $89^{\mathrm{b}}$ & $31.0^{\mathrm{b}}$ & $95^{\mathrm{a}}$ & $17.74^{\mathrm{a}}$ & $1677^{\mathrm{a}}$ \\
\hline
\end{tabular}

Radicle Emergence $(R E)$ : Germination Speed Index (GSI); Germination percentage (G); Seedling Length (SL); Seed Vigour Index (SVI).

*Means that do not share a letter are significantly different $(p<0.05)$ according to the Tukey's test

Table 4. Effect of varying Agar/l-Carrageenan (AC) coating concentrations on seed growth at $80 \%$ moisture

\begin{tabular}{llllll}
\hline Sample code & $R E(\%)$ & $G S I$ & $G(\%)$ & $S L(\mathrm{~cm})$ & $S V I$ \\
\hline Control & $79^{\mathrm{a}^{\mathrm{a}}}$ & $29.7^{\mathrm{a}}$ & $93^{\mathrm{a}}$ & $17.37^{\mathrm{a}}$ & $1607^{\mathrm{a}}$ \\
AC2 & $90^{\mathrm{a}}$ & $31.3^{\mathrm{a}}$ & $93^{\mathrm{a}}$ & $17.20^{\mathrm{a}}$ & $1604^{\mathrm{a}}$ \\
AC4 & $90^{\mathrm{a}}$ & $31.3^{\mathrm{a}}$ & $92^{\mathrm{a}}$ & $17.70^{\mathrm{a}}$ & $1619^{\mathrm{a}}$ \\
AC8 & $89^{\mathrm{a}}$ & $31.1^{\mathrm{a}}$ & $90^{\mathrm{a}}$ & $18.52^{\mathrm{a}}$ & $1671^{\mathrm{a}}$ \\
AC16 & $90^{\mathrm{a}}$ & $30.8^{\mathrm{a}}$ & $90^{\mathrm{a}}$ & $18.51^{\mathrm{a}}$ & $1671^{\mathrm{a}}$ \\
\hline
\end{tabular}

Radicle Emergence (RE); Germination Speed Index (GSI); Germination percentage (G); Seedling Length (SL); Seed Vigour Index (SVI). *Means that do not share a letter are significantly different $(p<0.05)$ according to the Tukey's test 
A significant effect on the $S L$ was found in both the coating type and the coating volume. The AC coated seeds showed significantly higher $S L$ than PA coated seeds $\left(F_{1,152}=7.27, P=0.008\right.$; Fig. $\left.3 \mathrm{~B}\right)$ and in terms of coating volume the $2 \mathrm{~mL}$ coated seeds were significantly shorter $\left(F_{3,152}=3.04, P=0.031\right.$; Fig. 3B) than $16 \mathrm{~mL}$ coated seeds. Nevertheless there was no interactive effect on the seeds, suggesting that the type and volume acted independently on $S L$.
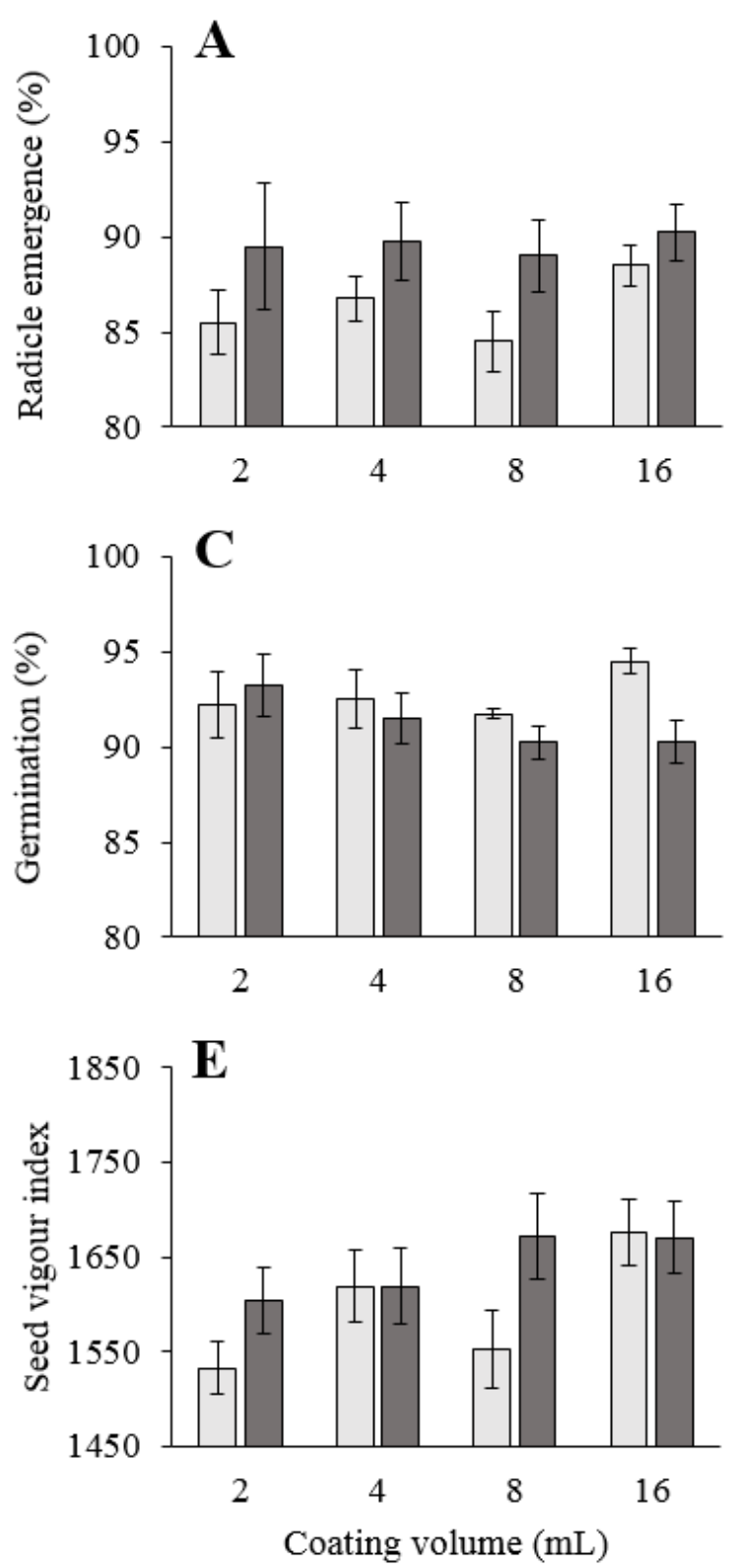

On the other hand, the $G$ and GSI showed no significant difference based on coating type, coating volume or interaction $(p>0.05$; Fig. $3 \mathrm{C}$ and $3 \mathrm{D})$. No significant effect in coating type and interaction was found in $S V I$ as well (Fig. 3E). However, it was still suspected that there may be a potential difference in seed vigour caused by the change in coating volume $\left(F_{3,152}=2.61, P=0.053\right)$, since the $P$-value was close to 0.05 .
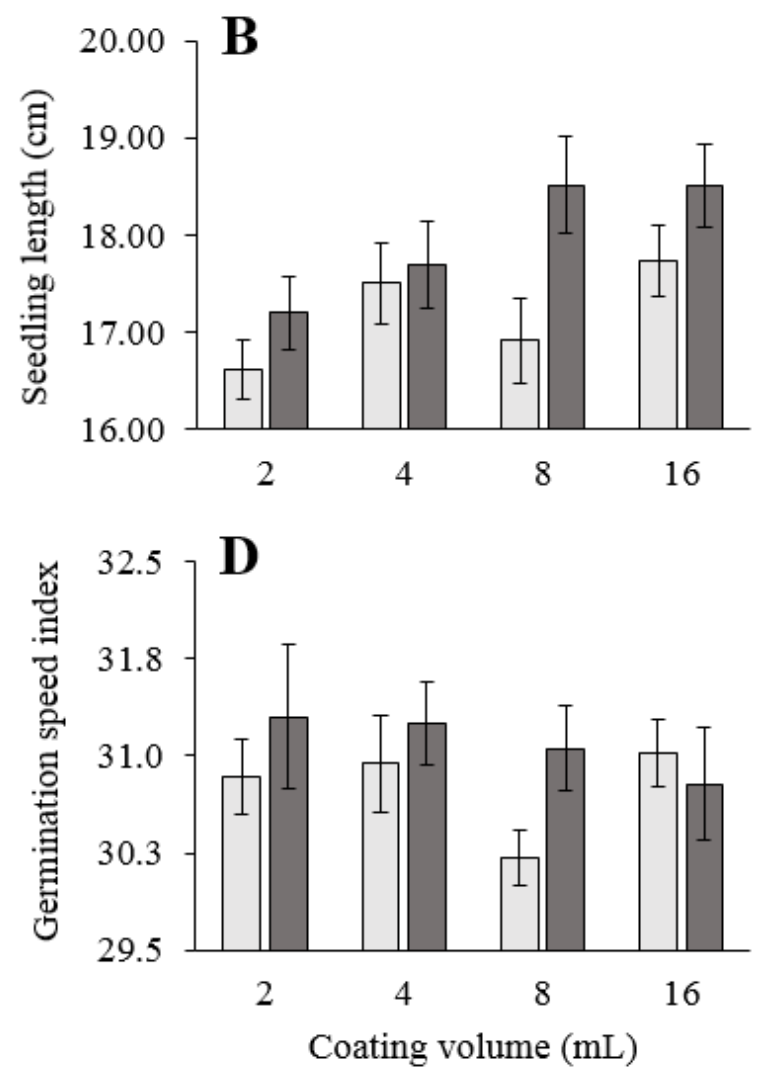

Fig. 3. The radicle emergence (A), seedling length (B), germination percentage (C), germination speed index (D) and seed vigour index (E) of Durum wheat seeds coated with 2, 4, 8 and $16 \mathrm{~mL}$ of polyacrylamide (light grey bars) and agar/l-carrageenan (dark grey bars) tested in $80 \%$ moisture level 

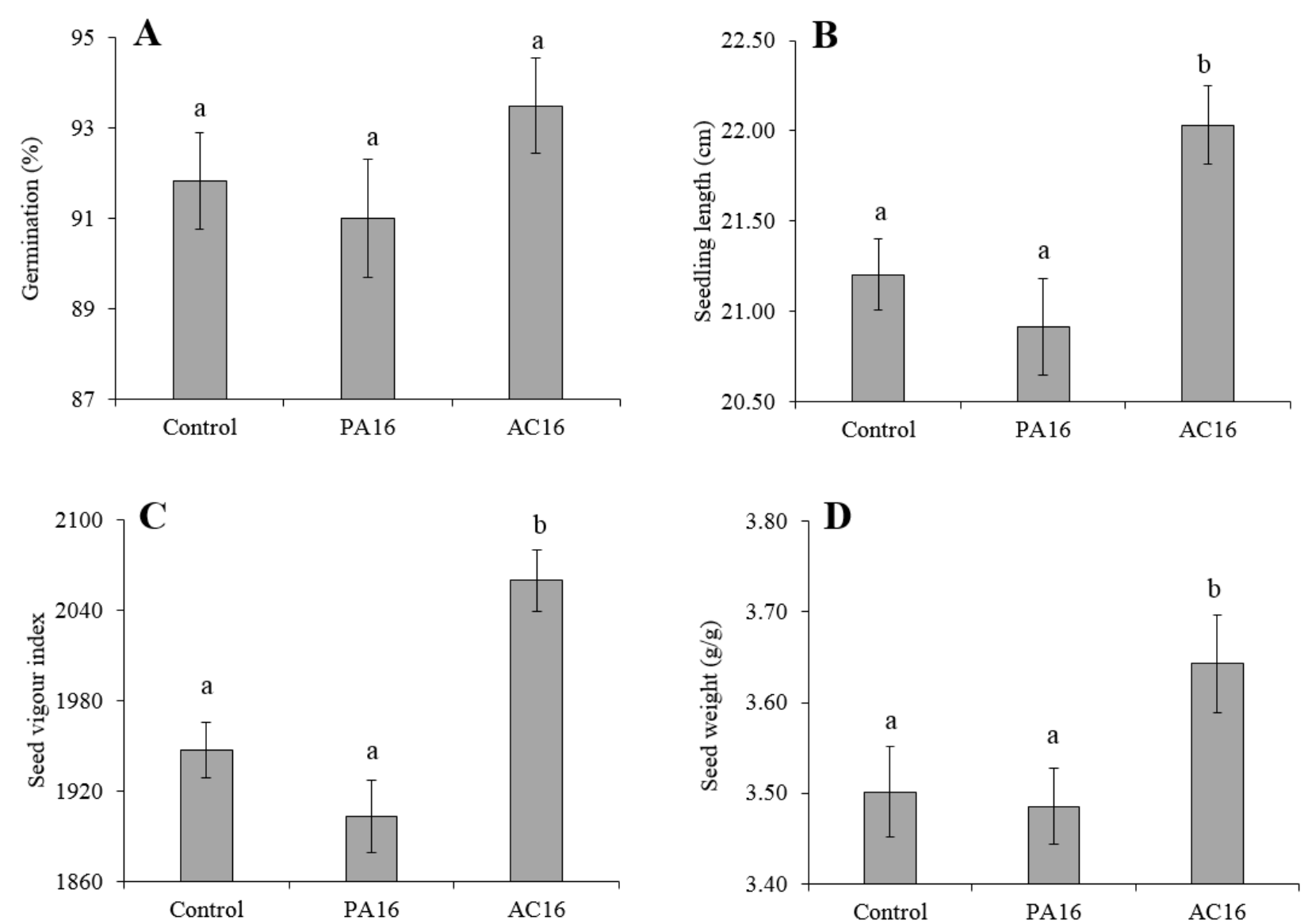

Fig. 4. The germination percentage (A), seedling length (B), seed vigour index (C) and seed weight (D) of uncoated (Control), 16 $\mathrm{mL}$ polyacrylamide (PA16) coated and $16 \mathrm{~mL}$ agar/l-carrageenan (AC16) coated Durum wheat seeds under $40 \%$ moisture level. Different lowercase letters represent significant $(p<0.05)$ differences according to the Tukey's test

Comparison of Growth Response between Polyacrylamide and Agar/l-Carrageenan Coated Seeds at 40\% Moisture Level

The mean values for $G, S L$ and $S V I$ results of AC16 coated seeds were higher than the mean values of PA16 coated seeds in all the data collected as presented in Fig. 4. It was also noticed that the level of abnormal seedlings (colour and appearance abnormalities as per ISTA guidelines) in the PA16 samples were higher than the control samples, while AC16 coated seeds had the lowest number of abnormal seedlings. However, statistical analysis revealed that the difference in the germination percentage between the control, PA16 and AC16 samples was not significant ( $p>0.05$; Fig. 4A).

A significant difference was found, however, in the $S L$ of AC16 coated seeds $\left(F_{2,267}=6.42, P=0.002\right.$; Fig. 4B). The AC16 sample had the longest shoot and root length compared to the control and PA16 coated seeds.

The beneficial effect of the AC16 coated seeds was mostly reflected in the $S V I$ values where the seed vigour was much higher than the control and the PA16 coated seeds $\left(F_{2,267}=14.74, p<0.005\right.$; Fig. $\left.4 \mathrm{C}\right)$.

\section{Difference in Seed Weight}

The $S W$ was calculated by dividing the fresh weight of the seeds at the end of the germination test by the initial dry weight of the seeds before the test (refer to section 2.2.). Statistical results showed that the seed weight ratio of the AC16 seed was significantly higher than that of the PA16 samples $\left(F_{2,69}=3.17, P=0.048\right.$; Fig. 4D). No statistically significant difference was observed between the control and the PA16 samples.

\section{Discussion}

Effect of Coating Types and Volumes on Seed Germination at Ideal Growth Condition

The type of SAP seed coatings can be adapted depending on the purpose of the application; to delay or speed up germination, inhibit rot, control pests, fertilise, 
or bind the seed to the soil. In most cases SAP coatings on seeds provide more efficient imbibition of water prior to germination and it is one of the reasons for improved seedling growth. Ideally, the polymer coating absorbs water from the surrounding soils and holds it at the seed surface, thus increasing both the germination speed and the total number of germinated seeds (Akelah, 2013).

From this study, it was found that the PA coating (refer to Table 3) on Durum wheat seeds favoured faster germination at $80 \%$ moisture level. In terms of $R E$, the germination rate of the untreated seed was significantly lower than all the other levels of PA coated seeds. This suggests that the PA coating helped to activate early germination and to promote breaking dormancy under favourable growth conditions. PA gels are known to improve water-retention capacity of soil, enhance root development, regulate plant growth and improve soil cluster structures (Akelah, 2013). However, PA is thought to have no direct nutritional effect on plants, but thought to improve intake of nutrients from the soil to the plants more effectively (Seybold, 1994), suggesting that the PA coatings improved seed germination mainly through improvement in the water absorption by seeds (Fig. 3C).

The findings based on our results demonstrated that the AC coating (refer to Table 4) on seeds encouraged more root and shoot development than the increase in germination capacity. This suggested that the AC coating acted in a different way to the PA coating. The AC coating is composed of sugar based carbohydrates with trace elements such as $\mathrm{Mg}, \mathrm{K}, \mathrm{Ca}, \mathrm{Na}$ and $\mathrm{S}$ as part of its chemical composition (Campo et al., 2009; Kelco, 2001; Prajapati et al., 2014). These may affect the seed growth by providing additional nutrition, or influence biological processes such as enzyme activity that promote root/shoot development (Njira and Nabwami, 2015).

In the case of $G$, the PA coating had a better effect on the seeds than the AC coating (Table 3 and 4). The $R E$ and $S L$ were significantly higher when using the $\mathrm{AC}$ coating under ideal growth condition ( $80 \%$ moisture). The effect was thought to be selective to the development of root/shoot cells. This was explained earlier as the possibility of the $\mathrm{AC}$ coating having higher levels of beneficial trace elements in the polymer compared to pure $(<0.05 \%$, AAm) PA coating.

In terms of coating volume, a significant difference in $S V I$ was found between the 2 and $16 \mathrm{~mL}$ coated seeds with PA coating (Table 3 ). In general the higher the coating volume, the greater the effect on the growth of the seeds for PA coated seeds.

The mean values of PA8 coated seeds tended to drop considerably compared to PA4 and PA16 coated samples in all parameters. Although no statistically significant difference was found, it was still worth noting that PA8 sample in particular seemed to inhibit the germination capacity and the growth of the seeds.
Based on this observation the coating volumes that provided a positive effect on the seeds were: 4 and 16 $\mathrm{mL}$ for the PA coating. In case of the AC coating, as the coating volume increased the mean values for $G$ and the GSI reduced. However, the mean values of $S L$ and $S V I$ showed an increase.

We hypothesise that the reduction in $G$ for the AC coated seeds was caused by an increase in the coating thickness, since hydrogel coating can sometimes reduce the germination percentage and the speed due to reduced aeration around the seeds (Landis and Haase, 2012). The effect of increased coating thickness can be further supported by the observed growth promoting effect on the seeds. The amount of trace elements present in the coating would increase and become more available to the seeds if the coating thickness increased.

The $S V I$ was used to decide the best coating volume for further investigation since the parameter is based on multiplication of $G$ and the corresponding $S L$. The samples selected for further comparison of seed growth at low moisture level were the PA16 and AC16 samples.

\section{Effect of Seed Coatings on Germination Performance under Low Moisture Level}

Seed growth between PA16, AC16 and control (uncoated seeds) was compared at $40 \%$ moisture level (drought simulated condition) as shown in Fig. 4. No significant difference was found in the $G$ between the samples (Fig. 4A). Whilst the observed differences were not of statistical significance, the higher mean germination percentage of AC16 coated seeds than those of the PA16 and the control samples appear to be of biological significance. In terms of $S L, S V I$ and $S W$ (Fig. 4B-4D), the AC16 sample performed significantly better than the PA16 and the control samples. In general the PA16 sample performed worse than the uncoated samples.

The results support that there was an advantage in using our natural blended hydrogel coating on the seeds over the synthetic PA coating under drought simulated conditions. The AC coating has helped promote faster seedling growth under both ideal and less than ideal conditions by promoting root/shoot development of seeds. This characteristic was also confirmed by the increase in $S W$.

It was thought that the increase in $S W$ (Fig. 4D) was due to an increase in biological mass or an increase in water content of the seedlings. Since both PA and AC coatings are based on SAPs which have a strong capacity to absorb water, the two samples (PA16 and AC16) were both expected to perform similarly in drought conditions. However, the mean $S W$ of the PA16 sample was slightly lower than the mean $S W$ of the control, which indicated that the seed weight gain was less likely due to the increase in water absorption by the seeds. The weight gain of seeds was thought to be more likely caused by 
the increase in seedling biomass. Further studies are required to investigate the reason behind the weight gain of the fresh seeds.

\section{Conclusion}

The synthetic PA coating on Durum wheat seeds showed some healthy seed growth effect under ideal growth conditions $(80 \%$ moisture level). The improvement in seedling performance was focused on the $R E, G S I$ and SVI compared to the uncoated seeds. However, the PA coating did not show any significant improvement in less than ideal growth conditions.

In drought simulated conditions $(40 \%$ moisture level), the AC coating showed a significant improvement in seed growth performance when compared to both the PA coated seeds and the uncoated seeds. In fact the PA coating had a negative effect on the seeds when compared to the uncoated seeds in drought simulated condition, showing low $G$, shorter $S L$, low $S V I$ and lowest $S W$. The beneficial effect of the AC coating on the seeds was particularly observed in the improvement in $S L$, increased biomass and higher $S V I$.

From the study it was found that the natural AC hydrogel coating on Durum wheat seeds showed better potential to promote seed growth under drought stress than the synthetic PA coatings. It has also been shown that the AC coating performed better than the uncoated seeds.

In conclusion the novel AC hydrogel coating showed an advantage over the synthetic PA coating in terms of seedling growth under drought stress, material safety and production cost. Further up-scaled investigations are being carried out in a greenhouse for the growth promoting effect of AC hydrogel coatings and it is anticipated that this natural seed coating can contribute to future food sustainability.

\section{Acknowledgement}

This project was supported by the Athlone Institute of Technology President's Seed Fund 2014 and Agri Aware, an Irish charitable trust funded by the farming and agri-food industry. We would like to thank the Department of Agriculture, Food and the Marine (Backweston, Celbridge, Co. Kildare, Ireland) for their seed testing facilities and RAGT semenses (France) for their generous supply of Durum wheat seeds.

\section{Author's Contributions}

All authors contributed equally to this work in the design of experiment.

Noreen Morris and Clement Higginbotham: Developed the formulation of hydrogels.

Maya Hotta: Conducted the seed analysis.
James Kennedy: Performed statistical analysis on the collected data. All authors discussed the results and implications and commented on the manuscript at all stages.

\section{Ethics}

This article is original and contains unpublished material. The corresponding author confirms that all of the other authors have read and approved the manuscript and that no ethical issues are involved.

\section{References}

Akelah, A., 2013. Functionalized Polymeric Materials in Agriculture and the Food Industry. 1st Edn., Springer Science and Business Media, New York, ISBN-10: 1461470617, pp: 367.

Bonfim, F., R. Dores, E. Martins and V. Casali, 2010. Germination and vigor of lettuce seeds (Lactuca sativa L.) pelleted with homeopathic preparations Alumina and Calcarea carbonica subjected to toxic levels of aluminum. Int. J. High Dilut. Res., 9: 138-146.

Campo, V.L., D.F. Kawano, D.B.D. Silva and I. Carvalho, 2009. Carrageenans: Biological properties, chemical modifications and structural analysis-a review. Carbohydrate Polymers, 77: 167-180. DOI: 10.1016/j.carbpol.2009.01.020

Caulfield, M.J., X. Hao, G.G. Qiao and D.H. Solomon, 2003. Degradation on polyacrylamides. Part II. Polyacrylamide gels. Polymer, 44: 3817-3826. DOI: $10.1016 / \mathrm{S} 0032-3861(03) 00330-6$

Kelco, C.P., 2001. GENU ${ }^{\circledR}$ Carrageenan Book. CP Kelco ApS, Lille Skensved.

Cregut, M. and E. Rondags, 2013. New insights in agar biorefinery with arylsulphatase activities. Process Biochem., 48: 1861-1871. DOI: $10.1016 /$ j.procbio.2013.09.020

Cyber Colloids Ltd, (n.d.). Introductoin to Agar.

Ekebafe, L.O., D.E. Ogbeifun and F.E. Okieimen, 2011. Polymer applications in agriculture. Biokemistri, 23: 81-89.

FAO, 2016. World food situatuin: FAO cereal supply demand brief. Food and Agriculture Organization.

FDA, 2015. Code of Federal Regulations Title 21, Food and Drugs, Part 173. U.S. Food and Drug Administration.

Guan, Y., H. Cui, W. Ma, Y. Zheng and Y. Tian et al., 2014. An enhanced drought-tolerant method using SA-loaded PAMPS polymer materials applied on tobacco pelleted seeds. Sci. World J., 2014: 1-9. DOI: $10.1155 / 2014 / 752658$

Gupta, P.C., 1993. Seed Vigour Testing. In: Handbook of Seed Testing, Agarwal, P.K. (Ed.), National Seed Corporation, New Delhi, pp: 242-249. 
Imeson, A.P., 2000. Carrageenan. In: Handbook of Hydrocolloids, Phillips, G.O. and P.A. Williams (Eds.), Woodhead Publishing Ltd, Cambridge, pp: $87-102$.

ISTA, 2015. International rules for seed testing. International Seed Testing Association.

Kharkale, S.S., P.S. Agrawal and L.J. Paliwal, 2011. Effect of organic contaminations on seed germination studies in tritium Aestivum (L.). Int. J. Current Biol. Medical Sci., 1: 35-38.

Kneipp, J., 2008. Durum wheat production. NSW Department of Primary Industries, New South Wales.

Njira, K.O.W. and J. Nabwami, 2015. A review of effects of nutrient elements on crop quality. Afr. J. Food, Agric. Nutrit. Develop., 15: 9777-9793.

Lamhamdi, M., A. Bakrim, A. Aarab, R. Lafont and F. Sayah, 2011. Lead phytotoxicity on wheat (Triticum aestivum L.) seed germination and seedlings growth. Comptes Rendus Biologies, 334: 118-126. DOI: 10.1016/j.crvi.2010.12.006

Landis, T.D. and D.L. Haase, 2012. Applications of Hydrogels in the Nursery and During Outplanting. In: Forest and Conservation Nursery Associations2011, Haase, D.L., J.R. Pinto and L.E. Riley, (Eds.), United States Department of Agriculture, pp: 53-58.

Lyons, J.G., L.M. Geever, M.J.D. Nugent, J.E. Kennedy and C.L. Higginbotham, 2009. Development and characterisation of an agar-polyvinyl alcohol blend hydrogel. J. Mechanical Behavior Biomed. Mater., 2: 485-493. DOI: 10.1016/j.jmbbm.2008.12.003

Martin, A.N., P.J. Sinko and Y. Singh, 2011. Martin's Physical Pharmacy and Pharmaceutical Sciences: Physical Chemical and Biopharmaceutical Principles in the Pharmaceutical Sciences. 6th Edn., Lippincott Williams and Wilkins, Philadelphia, Pa., ISBN-10: 0781797667, pp: 659.

Meena, R., K. Prasad and A.K. Siddhanta, 2009. Development of a stable hydrogel network based on agar-kappa-carrageenan blend cross-linked with genipin. Food Hydrocolloids, 23: 497-509.

DOI: 10.1016/j.foodhyd.2008.03.008

NASA, 2015. Global climate change: The current and future consequences of global change. NASA.

Nijhuis, M., 2014. When the snows fail. National Geographic, 226: 58-73.

Pereira, L., A. Sousa, H. Coelho, A.M. Amado and P.J.A. Ribeiro-Claro, 2003. Use of FTIR, FT-Raman and ${ }^{13} \mathrm{C}-\mathrm{NMR}$ spectroscopy for identification of some seaweed phycocolloids. Biomolecular Eng., 20: 223-228. DOI: 10.1016/S1389-0344(03)00058-3

Prajapati, V.D., P.M. Maheriya, G.K. Jani and H.K. Solanki, 2014. Carrageenan: A natural seaweed polysaccharide and its applications. Carbohydrate Polymers, 105: 97-112.

DOI: 10.1016/j.carbpol.2014.01.067
Puoci, F., F. Iemma, U.G. Spizzirri, G. Cirillo and M. Curcio et al., 2008. Polymer in agriculture: A review. Am. J. Agric. Biol. Sci., 3: 299-314. DOI: 10.3844/ajabssp.2008.299.314

Rocha, C.M.R., H.K.S. Souza, N.F. Magalhães, C.T. Andrade and M.P. Gonçalves, 2014. Rheological and structural characterization of agar/whey proteins insoluble complexes. Carbohydrate Polymers, 110: 345-353. DOI: 10.1016/j.carbpol.2014.04.015

Rudzinski, W.E., A.M. Dave, U.H. Vaishnav, S.G. Kumbar and A.R. Kulkarni et al., 2002. Hydrogels as controlled release devices in agriculture. Designed Monomers Polymers, 5: 39-65.

DOI: $10.1163 / 156855502760151580$

Seybold, C.A., 1994. Polyacrylamide review: Soil conditioning and environmental fate. Commun. Soil Sci. Plant Analysis, 25: 2171-2185. DOI: $10.1080 / 00103629409369180$

Smith, J. and L. Hong-Shum, 2003. Food Additives Data Book. 1st Edn., Wiley, Oxford, ISBN-10: 0632063955, pp: 1040.

Sojka, R.E., D.L. Bjorneberg, J.A. Entry, R.D. Lentz and W.J. Orts, 2007. Polyacrylamide in agriculture and environmental land management. Adv. Agronomy, 92: 75-162. DOI: 10.1016/S0065-2113(04)92002-0

Taylor, R.D. and W.W. Koo, 2012. 2012 Outlook of the U.S. and World Wheat Industries, 2012-2021. North Dakota State University, North Dakota.

Yang, L., Y. Yang, Z. Chen, C. Guo and S. Li, 2014. Influence of super absorbent polymer on soil water retention, seed germination and plant survivals for rocky slopes eco-engineering. Ecol. Eng., 62: 27-32. DOI: 10.1016/j.ecoleng.2013.10.019

Zeng, D.F. and H. Wang, 2010. Preparation of a novel highly effective and environmental friendly wheat seed coating agent. Agric. Sci. China, 9: 937-941. DOI: 10.1016/S1671-2927(09)60174-7

Zeng, D.F. and L. Zhang, 2010. A novel environmentally friendly soybean seed-coating agent. Acta Agric. Scandinavica, Sect. B-Soil Plant Sci., 60: 545-551. DOI: 10.1080/09064710903334256

ZernoExport, $2013 . \quad$ Wheat. http://www.zernoexport.com/en/catalog/catalog1/ps henica

Zohuriaan-Mehr, M.J. and K. Kabiri, 2008. Superabsorbent polymer materials: A review. Iranian Polymer J., 17: 451-477. 